\title{
Dental Impression
}

National Cancer Institute

\section{Source}

National Cancer Institute. Dental Impression. NCI Thesaurus. Code C73514.

A procedure used to acquire a neg ative reproduction of an oral structure for the purpose

of producing a positive model or cast of the structure upon which restorations,

prostheses, and dentures are fabricated. 